\title{
A STUDY OF THE SOLUBILITY OF BIODEGRADABLE FOAMS OF THERMOPLASTIC STARCH
}

\author{
Marcin Mitrus', Maciej Combrzyński' ${ }^{1}$, Karol Kupryaniuk', \\ Agnieszka Wójtowicz' ${ }^{1}$ Tomasz Oniszczuk' ${ }^{1}$ Magdalena Kręcisz'1, \\ Arkadiusz Matysiak², Anna Smurzyńska ${ }^{3}$, Leszek Mościcki ${ }^{1}$
}

1 Department of Food Process Engineering, University of Life Sciences in Lublin, Doświadczalna 44 St., 20-280 Lublin, Poland, e-mail: marcin.mitrus@up.lublin.pl

2 POL-FOODS Sp. z o.o., Kolejowa 1d St., 19-335 Prostki, Poland

${ }^{3}$ Institute of Biosystems Engineering, University of Life Sciences in Poznań, Wojska Polskiego 50 St., 60-637 Poznań, Poland

Received: 2016.05.18 Accepted: 2016.08.08 Published: 2016.09.30

\begin{abstract}
The paper presents the results of a study on the water absorption capacity and solubility of biodegradable starch foams produced with single-screw extruder TS-45 with $\mathrm{L} / \mathrm{D}=12$. Two different moulding dies were used: one with a circular hole with the diameter of $3 \mathrm{~mm}$ and one with a ring hole with the inner diameter of $5 \mathrm{~mm}$. During the extrusion process, the temperature of the cylinder ranged from 80 to $130^{\circ} \mathrm{C}$ and the screw speeds applied were: 100 and $130 \mathrm{rpm}$. For the application of the ring die, it was observed that regardless of the speed of the screw, the use of the raw material of higher moisture content led to the production of materials with higher solubility. As a result, the obtained materials revealed solubility at a level of $40 \%$. The results demonstrate good solubility of the starchy fillers of the packaging, which may indicate their susceptibility to decomposition in the conditions of high ambient humidity. A statistical analysis showed a significant impact of moisture of the raw material on the WSI of starch foams used irrespective of the other parameters of the extrusion-cooking process. The raw material moisture had a significant effect on the water absorption capacity of only TPS foams produced in the ring die at the screw speed of $100 \mathrm{rpm}$.
\end{abstract}

Keywords: foams, biodegradable materials, thermoplastic starch, extrusion-cooking, solubility

\section{INTRODUCTION}

The manufacturers of foamed packaging materials are put under increasing pressure exerted by new laws and regulations on environmental protection and waste disposal [Nabar, Draybuck and Narayan 2006, Nabar and Narayan 2006, Yang et al. 2013, Zhou et al. 2006]. They present a serious problem for enterprises and municipalities because such products are difficult to manage, do not degrade in the environment and their recycling is often unprofitable (excessive costs of transportation and disposal). Consequently, more attention is paid to the possibility of recycling the packaging, especially single-use mate- rials. The market expects manufacturers to produce environmentally-safe materials which meet the usability requirements at the same time. The mounting interest in environmentally-friendly materials has encouraged the design and development of foamed materials made of natural raw materials and intended for packaging [Janssen and Mościcki 2009, Tatarka and Cinningham 1998, Willet and Shogren 2002].

The manufacturers of biodegradable packaging materials are looking towards the use of starch, protein, and cellulose. Biodegradable materials made from biopolymers, such as starch and cellulose, are suitable for composting [Vaverková and Adamcowá 2015]. Hence the attempts of tak- 
ing advantage of arable crops in the manufacture of biopolymers [Bastioli 2005, Cinelli et al. 2006, Combrzyński et al. 2012, Lawton et al. 2004, Mitrus and Moscicki 2014, Oniszczuk et al. 2015, Parra et al. 2006, Pushpadass et al. 2008, Van Tuil et al. 2001, Yang et al. 2013, Zhang and Sun 2007].

Foamed starch materials are used in packaging-making, in the production of sound insulators, sealants, flotation devices and various types of sports and recreation aids [Zhang and Sun 2007]. Starch-based foam materials can have an even greater commercial potential if their manufacturing process is further adjusted to product a variety of products with the most sought-after properties that can be obtained by, for example, mixing with plastics, or the use of natural substances that enhance the properties of the final product (e.g. fibre) [Cinelli et al. 2006, Oniszczuk et al. 2015]. Besides the functional additives based on petrochemicals, there are also natural and biodegradable materials that, when used in a reasonable manner, can add the desired characteristics to any marketed material. Such substances are, e.g. polyvinyl alcohol, polylactic acid (PLA) and hydrophobic additives: polycaprolactone (PCL), cellulose acetate and aliphatic-aromatic copolyesters.

Starch-based foam materials are very light and can be used as fillers in transportation packaging [Wang et al. 2005]. Yet, biodegradable foam materials based on vegetable raw materials are relatively brittle, show poor resistance to water and dissolve completely, as opposed to synthetic foams which are totally inert to moisture [Bastioli 2005, Chaudhary et al. 2008, Mitrus and Moscicki 2014, Parra et al. 2006, Salgado et al. 2008, Shogren et al. 2002, Sivertsen 2007, Soykeabkaew et al. 2004, Van Tuil et al. 2001, Willet and Shogren 2002, Zhang and Sun 2007, $\mathrm{Xu}$ et al. 2005]. Another disadvantage of such materials is a demanding production process and limitations in the development of the optimum structures of foam cells required by the recipients. The absence of ready-made solutions for industry is a challenge for the researchers trying to obtain fully functional and biodegradable foam materials that could be broadly applicable in the production of packaging.

The aim of the research was to determine the effect of selected parameters of the extrusioncooking process on the water absorption capacity and solubility in water of thermoplastic starch foams. These are the indirect methods of assess- ing the intensity of physico-chemical transformation of starch. In addition, the examination can determine the capacity for the potential biodegradability of obtained starch materials through its composting in a high humidity environment.

\section{MATERIALS AND METHODS}

The basic raw material used in the tests was potato starch of the Superior Standard type (supplier: PPZ Trzemeszno Sp. z o.o.). Technical glycerol was used as a plasticizer. The potato starch and glycerol were used to prepare raw material mixtures with $20 \%$ of glycerol content in the weight of the mixture. Samples were mixed using a laboratory mixer ribbon. The preliminary examination revealed that the raw material with the moisture content below $17 \%$ and above $19 \%$ significantly hindered the collection of the material by the extruder: the material adhered to the screw at the charging hopper and the production was halted several times. To remedy the situation, the raw material was moisturised up to 17,18 and $19 \%$ of dry matter and stored in closed containers for 24 hours to make the mixture more homogeneous. Immediately before extrusion, the samples were mixed again for 10 minutes to obtain a loose and powdered structure of the mixture.

TPS foams were made with a single-screw extruder equipped with a plasticizer system with the screw length/diameter ratio of $\mathrm{L} / \mathrm{D}=12 / 1$. Two different moulding dies were used in the tests: one with a circular hole with the diameter of 3 $\mathrm{mm}$ (M1) and one with a ring hole with the inner diameter of $5 \mathrm{~mm}$ (M2). During the extrusion process, the temperature of the cylinder ranged from 80 to $130^{\circ} \mathrm{C}$ and the screw speeds applied were: 100 and $130 \mathrm{rpm}$. The product was shaped into foams of approximately $2-3 \mathrm{~cm}$-long using a high-speed cutter. The foam product obtained in the extrusion-cooking was stabilized at the room temperature in a tray dryer and then stored in sealed polyethylene bags.

The solubility of thermoplastic starch foams was assessed indirectly by measuring their water absorption capacity (WAI) and solubility in cold water (WSI). The WAI was established with the centrifuge method with modification [Mitrus and Moscicki 2014]. The obtained extrudate was ground in a laboratory mill to a grain size below $0.3 \mathrm{~mm}$. A suspension was obtained from a sample of the extrudate of 0.7 grams and $7 \mathrm{ml}$ of dis- 
tilled water at $20^{\circ} \mathrm{C}$ by continuous mixing for 30 minutes. The suspension was centrifuged at 250 $\mathrm{s}^{-1}$ for 10 minutes in laboratory centrifuge T24D. The filtrate was collected from the obtained gel and the gel was weighed. The WAI was determined in the following formula:

$$
W A I=\frac{m_{g}}{m_{s}}\left[\mathrm{gg}^{-1}\right]
$$

where: $w_{g}-$ gel weight $[\mathrm{g}]$,

$$
w_{s}^{g} \text { - sample weight }[\mathrm{g}] \text {. }
$$

The measurements were done in 3 replications. The water solubility index (WSI) was determined from the amount of the dry matter left after the evaporation of the filtrate obtained during the WAI test [Mitrus and Moscicki 2014]. The results were calculated according to the formula:

$$
W S I=\frac{w_{d s}}{w_{s}} \cdot 100[\%]
$$

where: $w_{d s}-$ dry matter volume in the filtrate $[\mathrm{g}]$, $W_{s}$ - sample weight [g].

The measurements were done in 3 replications.

The results were processed with Satistica 6.0 performing a single-factor analysis of variance (ANOVA). Also the F-test and Kruskal-Wallis test were carried out and the significance of differences between the average values was established at the confidence level of $95 \%$.

\section{RESULTS AND DISCUSSION}

During the extrusion-cooking process, starch is subject to a dramatic physico-chemical transformation. In indirect terms, the intensity of this transformation can be assessed by the measurement of the water absorption capacity and water solubility of starch. At the elevated temperature and in the presence of water, the starch is partly or even completely gelatinized. Through this process, modified starch can absorb larger amounts of water than native starch. During the intense pressure and thermal processing, the degradation of starch also takes place. Through the action of high temperature, caused by high friction and shear forces, there is a fragmentation of polymer chains (amylose and amylopectin) which are the main components of starch. As a result, in cold water starch reveals increased solubility and reduced water absorption [Thomas and Atwell 1999].
The research demonstrated the impact of selected parameters of the extrusion-cooking process on the water absorption capacity and solubility in water of thermoplastic starch foams. Figure 1 shows the change in the absorption of water by TPS foams produced with the M1 die with the hole diameter of $3 \mathrm{~mm}$ at different rotational speeds of the screw.

Mitrus and Moscicki [2014] reported that foam materials made from corn starch in extruder TS-45 display the water absorption index of $1.46 \mathrm{~g} \mathrm{~g}^{-1}$. During this tests, it was found that the potato starch foams produced at the speed of 100 rpm displayed greater water absorption (almost

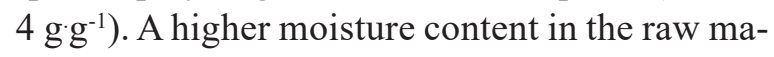
terial permitted the manufacture of foams with the higher WAI. A larger water content resulted in increased starch gelatinization. Additionally, the presence of glycerol in the raw material mixture, with the addition of water, significantly lowered the glass transition temperature of starch and facilitated its processing. The application of a higher screw speed reduced the water absorption property of obtained foams. Due to the shorter residence time in the extruder, and despite an increase in the moisture content of the raw material, there was no significant change in the water absorption capacity of foams produced at the screw speed of $130 \mathrm{rpm}$.

The examination of foam materials from TPS obtained with the M1 die showed that the use of raw material with a higher moisture content had an adverse effect on their solubility (Figure 2). The least moistured (17\% moisture) raw material mixture caused a relatively intense thermal

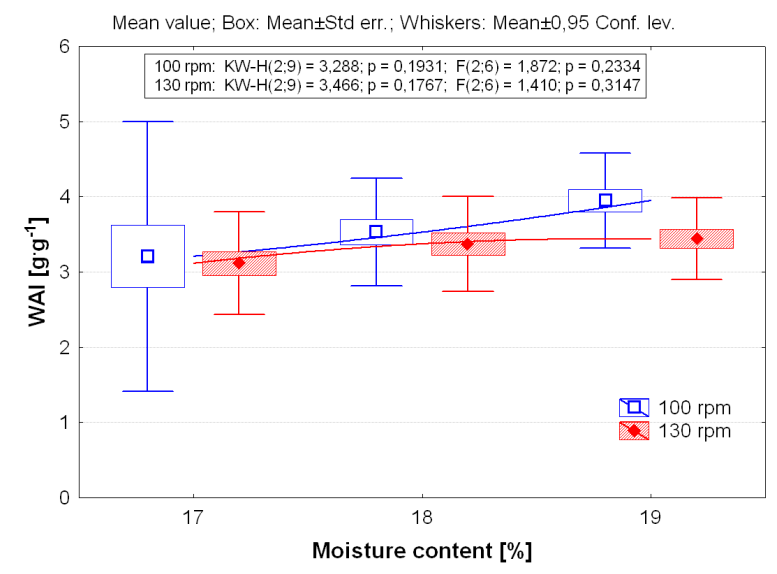

Figure 1. Water absorption capacity of TPS foams produced with the M1 die 


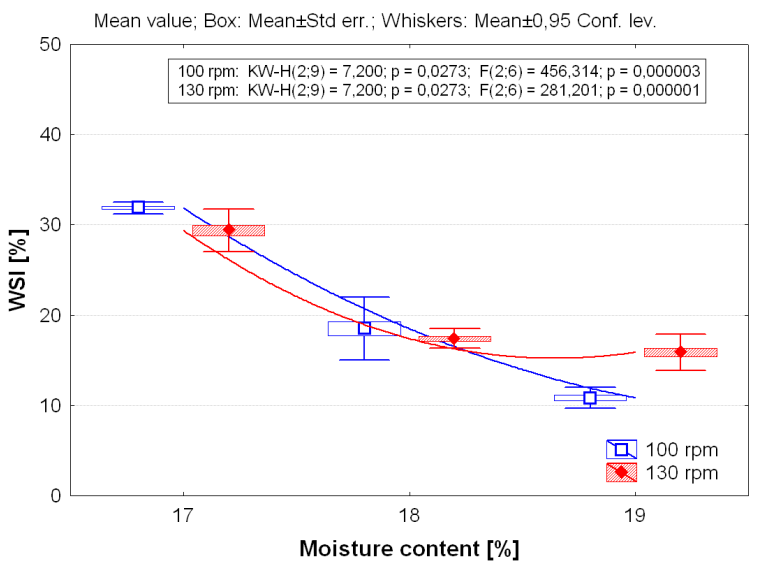

Figure 2. Solubility of TPS foams produced with the M1 die

and mechanical transformation, resulting in the solubility at $32 \%$ - the highest for these samples. A greater availability of water, acting like a lubricant, considerably reduces friction inside the extruder, thus limiting the mechanical and thermal degradation of starch. A larger screw speed resulted in the reduced WSI value. As in the case of WAI, shorter residence time of the material in the cylinder decreased the intensity of starch modification. Mitrus and Moscicki [2014] reported the manufacture of corn packaging foams with a lower WSI value at $24 \%$.

The use of the M2 die with the ring opening resulted in the formation of the thermoplastic starch foams with variable water absorption and solubility as compared with the foams obtained in the circular die (Figure 3).

During the study, it was found that the use of varying moisture content had an insignificant effect on the water absorption capacity of the obtained foam products. Also the use of a higher screw speed during the production of extruded foams resulted in reduced water absorption as the material had a shorter residence time in the extruder.

The use of the ring die largely increased the solubility of the obtained starch foams in water (Figure 4). Most probably, the ring die caused the pressure and shear forces to build up inside the extruder cylinder. Consequently, upon leaving the die, the material expands rapidly, which can lead to extra fragmentation of the starch due to tearing.

When the ring die was used, it was observed that regardless of the speed of the screw, during the pressure and thermal treatment, the use of the raw material of higher moisture content led to the production of materials with higher solubility. As a result, the obtained materials revealed solubility at a level of even $40 \%$. Probably, besides elevated pressure, the use of the ring die intensifies the action of shear forces in the die opening. What followed, the starch was subject to a more intense physico-chemical transformation. All those impacts translate into the degradation of starch, thereby the WSI for the obtained foam material rises compared with the starch foams made on the full die.

The statistical analysis performed (Table 1) showed a significant impact of the moisture level in the raw material on the WSI of starch foams irrespective of the other parameters of the extrusion-cooking process. This is also indicated by the high $\mathrm{F}$ test values. The raw material moisture had a significant effect only on the water absorption capacity of TPS foams produced in the ring die at the screw speed of $100 \mathrm{rpm}$.

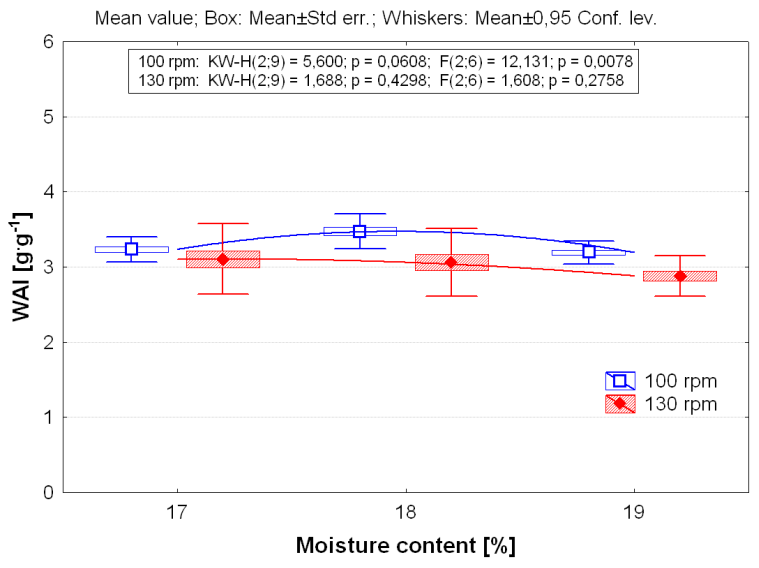

Figure 3. Water absorption capacity of TPS foams produced with the M2 die

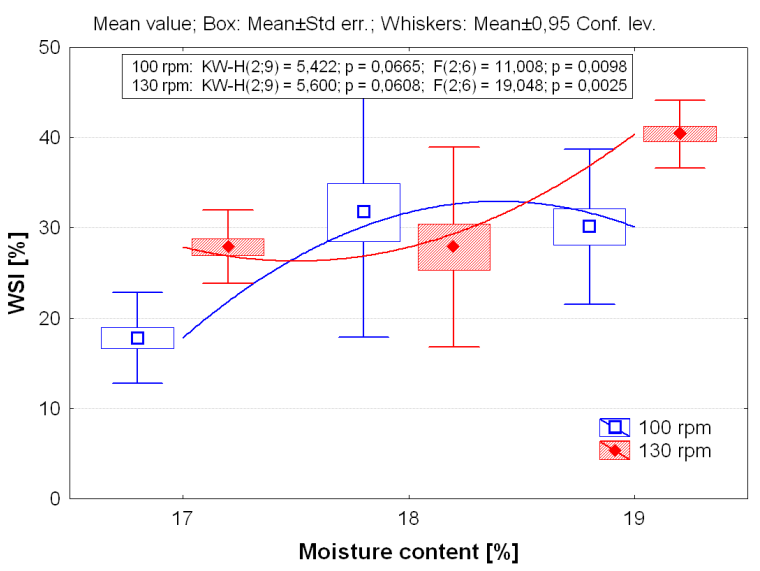

Figure 4. Solubility of TPS foams produced with the M2 die 
Table 1. The analysis of variance of WAI and WSI of starch foams depends on the processing conditions

\begin{tabular}{|c|c|c|c|c|c|c|c|c|c|c|}
\hline Variable & Die type & $\begin{array}{c}\text { Source of } \\
\text { variation } \\
\text { [rpm] }\end{array}$ & $\begin{array}{c}\text { SS } \\
\text { effect }\end{array}$ & $\begin{array}{c}\text { df } \\
\text { effect }\end{array}$ & $\begin{array}{c}\text { MS } \\
\text { effect }\end{array}$ & $\begin{array}{l}\text { SS } \\
\text { error }\end{array}$ & $\begin{array}{l}\mathrm{df} \\
\text { error }\end{array}$ & $\begin{array}{l}\text { MS } \\
\text { error }\end{array}$ & C & $\mathrm{p}$ \\
\hline \multirow{4}{*}{ WAI } & \multirow{2}{*}{ M1 } & 100 & 0.8326 & 2 & 0.4163 & 1.3340 & 6 & 0.222 & 1.8724 & 0.2334 \\
\hline & & 130 & 0.1763 & 2 & 0.0881 & 0.3751 & 6 & 0.063 & 1.4104 & 0.3147 \\
\hline & \multirow{2}{*}{ M2 } & 100 & 0.13654 & 2 & 0.0683 & 0.0337 & 6 & 0.006 & 12.1315 & 0.0077 \\
\hline & & 130 & 0.08553 & 2 & 0.0428 & 0.1594 & 6 & 0.026 & 1.6088 & 0.2757 \\
\hline \multirow{4}{*}{ WSI } & \multirow{2}{*}{ M1 } & 100 & 679.940 & 2 & 339.97 & 4.4702 & 6 & 0.745 & 456.3142 & 0.00000 \\
\hline & & 130 & 328.472 & 2 & 164.24 & 3.5043 & 6 & 0.584 & 281.2019 & 0.00001 \\
\hline & \multirow{2}{*}{ M2 } & 100 & 346.911 & 2 & 173.46 & 94.5361 & 6 & 15.756 & 11.0088 & 0.0098 \\
\hline & & 130 & 313.544 & 2 & 156.77 & 49.3820 & 6 & 8.230 & 19.0480 & 0.0025 \\
\hline
\end{tabular}

\section{CONCLUSIONS}

1. The type of die used in the production of foamed starch materials largely affects their water absorption and solubility properties. The use of the M2 ring die significantly increases the solubility of TPS foams.

2. The statistical analysis performed showed a significant impact of moisture of the raw material on the WSI of starch foams used irrespective of the other parameters of the extrusioncooking process. The increased moisture level of the raw material results in the reduced or increased WSI when the M1 and M2 die is used, respectively. The modified raw material moisture level had a significant effect on the water absorption capacity of TPS foams produced in the $\mathrm{M} 2$ ring die at the screw speed of $100 \mathrm{rpm}$.

3. The results demonstrate good solubility of the starchy fillers of the packaging, which may indicate their susceptibility to decomposition in the conditions of high ambient humidity.

\section{REFERENCES}

1. Bastioli C. 2005. Handbook of Biodegradable Polymers. Rapra Technology Limited, UK.

2. Chaudhary A.L., Miler M., Torley P.J., Sopade P.A., Halley P.J. 2008. Amylose content and chemical modification effects on the extrusion of thermoplastic starch from maize. Carbohydrate Polymers, 74, 907-913.

3. Cinelli P., Chiellini E., Lawton J.W., Imam S.H. 2006. Foamed articles based on potato starch, corn fibers and poly(vinyl alcohol). Polymer Degradation and Stability, 91, 1147-1155.

4. Combrzyński M., Mitrus M., Mościcki L., Oniszczuk T., Wójtowicz A. 2012. Selected aspects of thermoplastic starch production. TEKA Commission of Motorization and Energetics in Agriculture, 12(1), 25-29.

5. Janssen L.P.B.M., Moscicki L. (Eds.). 2011. Thermoplastic Starch. WILEY-VCH Verlag GmbH\& Co. KGaA, Weinheim, Germany.

6. Lawton J.W., Shogren R.L., Tiefenbacher K.F. 2004. Aspen fiber addition improves the mechanical properties of baked cornstarch foams. Industrial Crops and Products, 19(1), 41-48.

7. Mitrus M., Moscicki L. 2014. Extrusion-cooking of starch protective loose-fill foams. Chemical Engineering Research and Design, 92, 778-783.

8. Nabar Y.U., Draybuck D., Narayan R. 2006 Physicomechanical and hydrophobic properties of starch foams extruded with different biodegradable polymers. Journal of Applied Polymer Science, 102, 58-68.

9. Nabar Y., Narayan R. 2006. Analysis of the dynamic behavior of a starch foam extrusion process. Journal of Applied Polymer Science, 101, 3983-3995.

10. Oniszczuk T., Mitrus M., Wójtowicz A., Mościcki L. 2015. Addition of bark in the production of the starch-based composites. Przemysł Chemiczny, 94(10), 1748-1751.

11. Parra D.F., Carr L.G., Ponce P., Tadini C.C., Lugão A.B. 2006. Biodegradable foams made of cassava starch and fibers: Influence in the mechanical properties. Proceedings of the 2nd CIGR Section VI International Symposium on Future of Food Engineering, 26-28 April 2006, Warsaw, Poland.

12. Pushpadass H.A., Suresh Babu S.G., Weber R.W., Hanna M A. 2008. Extrusion of starch-based loosefill packaging foams: effects of temperature, moisture and talc on physical properties. Packaging Technology and Science, 21, 171-183.

13. Salgado P.R., Schmidt V.C., Molina Ortiz S.E., Mauri A.N., Laurindo J.B. 2008. Biodegradable foams based on cassava starch, sunflower proteins and cellulose fibers obtained by a baking process. 
Journal of Food Engineering, 85, 435-443.

14. Shogren R.L., Lawton J.W., Tiefenbacher K.F. 2002. Baked starch foams: starch modifications and additives improve process parameters, structure and properties. Industrial Crops and Products, $16,69-79$.

15. Sivertsen K. 2007. Polymer Foams. Polymer Physics, Spring, Massachusetts Institute of Technology, USA.

16. Soykeabkaew N., Supaphol P., Rujiravanit R. 2004. Preparation and characterization of jute- and flaxreinforced starch-based composite foams. Carbohydrate Polymers, 58, 53-63.

17. Tatarka P.D., Cunningham R. L. 1998. Properties of protective loose-fill foams. Journal of Applied Polymer Science, 67, 1157-1176

18. Thomas D.J., Atwell W.A. 1999. Starches. Eagan ${ }^{\circledR}$ Press, St. Paul, Minnesota, USA.

19. Van Tuil R., Van Heemst J., Schennink G. 2001. Potato Starch Based Resilient Thermoplastic Foams. In: Chiellini E., Gil H., Braunegg G., Buchert J., Gatenholm P., van der Zee M (Eds.): Biorelated Polymers: Sustainable Polymer Science and Technology. Kluwer Academic, 3-17, New York, USA.

20. Vaverková M.D., Adamcowá D. 2015. Biodegra- bility of bioplastic materials in a controlled composting environment. Journal of Ecological Engineering, 16(3), 155-160.

21. Wang L., Ganjyal G.M., Jones D.D., Weller C.L., Hanna M.A. 2005. Modeling of bubble growth dynamics and nonisothermal expansion in starchbased foams during extrusion. Advances in Polymer Technology, 24(1), 29-45.

22. Willett J.L., Shogren R.L. 2002. Processing and properties of extruded starch/polymer foams. Polymer, 43, 5935-5947.

23. Xu Y.X., Dzenis Y., Hanna M.A. 2005. Water solubility, thermal characteristics and biodegradability of extruded starch acetate foams. Industrial Crops and Products, 21(3), 361-368.

24. Yang Z., Graiver D., Narayan R. 2013. Extrusion of humidity-resistant starch foam sheets. Polymer Engineering and Science, 53(4), 857-867

25. Zhang J.F., Sun X. 2007. Biodegradable foams of poly(lactic acid)/starch. II. Cellular structure and water resistance. Journal of Applied Polymer Science, 106, 3058-3062.

26. Zhou J., Song J., Parker R. 2006. Structure and properties of starch-based foams prepared by microwave heating from extruded pellets. Carbohydrate Polymers, 63, 466-475. 